\title{
ELECCIONES LEGISLATIVAS EN ITALIA
}

\author{
PILAR MELLADO PRADO
}

Durante los dias 14 y 15 de junio de este año se celebraron en Italia elecciones legislativas para renovar la Cámara de Diputados y el Senado. De los resultados de estas últimas elecciones políticas puede destacarse, en primer lugar, el hecho de que la Democracia Cristiana mantiene e incluso mejora sus posiciones con nueve escaños más que en los anteriores comicios. En segundo lugar, se produce un avance - no tan importante como se esperaba - del Partido Socialista, que ha recibido el apoyo de antiguos votantes de los llamados partidos "laicos" (Socialdemócrata, Republicano y Liberal). Y en tercer lugar cabría destacar el importante retroceso que ha sufrido el Partido Comunista, que parece haber perdido votos en favor de los Verdes, formación política que aparece por primera vez en el panorama parlamentario italiano.

En definitiva, los italianos han votado mayoritariamente a los partidos integrantes de la coalición "pentapartita», fórmula que, a juicio de los observadores, parece la única posible a pesar del refuerzo de democristianos y socialistas.

A continuación reproducimos los resultados de estas elecciones legislativas señalando las diferencias en porcentaje de votos y en escaños con las anteriores. 
ELECCIONES LEGISLATIVAS 1987

\begin{tabular}{|l|rr|rr|}
\hline \multicolumn{5}{|c|}{ Cámara de Diputados } \\
\hline & \multicolumn{2}{|c|}{$\%$} & \multicolumn{2}{c|}{ Escaño } \\
\hline DC & 34,3 & $(+1,4)$ & 234 & $(+9)$ \\
\hline PCI & 26,6 & $(-3,3)$ & 177 & $(-21)$ \\
\hline PSI & 14,3 & $(+2,9)$ & 94 & $(+21)$ \\
\hline PSDI & 3,0 & $(-1,1)$ & 17 & $(-6)$ \\
\hline PRI & 3,7 & $(-1,4)$ & 21 & $(-8)$ \\
\hline PLI & 2,1 & $(-0,8)$ & 11 & $(-5)$ \\
\hline MSI & 5,9 & $(-0,9)$ & 35 & $(-7)$ \\
\hline RAD & 2,6 & $(+0,4)$ & 13 & $(+2)$ \\
\hline DP & 1,7 & $(+0,2)$ & 8 & $(+1)$ \\
\hline Verdes & 2,5 & $(+2,5)$ & 13 & $(+13)$ \\
\hline Psd'Az. & 0,4 & $(+0,1)$ & 2 & $(+1)$ \\
\hline Ven/Pens. & 0,8 & $(+0,5)$ & - & $(-1)$ \\
\hline PPST & 0,5 & $(=)$ & 3 & $(=)$ \\
\hline U. Vald. & 0,1 & $(=)$ & 1 & $(=)$ \\
\hline L. Lombarda & 0,5 & $(+0,5)$ & 1 & $(+1)$ \\
\hline Otros & 1,0 & $(-1,0)$ & $=$ & $(=)$ \\
\hline
\end{tabular}




\begin{tabular}{|l|rr|rr|}
\hline \multicolumn{5}{|c|}{ Senado } \\
\hline & \multicolumn{2}{|c|}{$\%$} & \multicolumn{2}{c|}{ Escaño } \\
\hline DC & 33,6 & $(+1,2)$ & 125 & $(+5)$ \\
\hline PCI & 28,3 & $(-2,5)$ & 100 & $(-7)$ \\
\hline PSI & 10,9 & $(-0,5)$ & 36 & $(-2)$ \\
\hline PSDI & 2,4 & $(-1,4)$ & 5 & $(-3)$ \\
\hline RAD & 1,8 & $(=)$ & 3 & $(+2)$ \\
\hline Psi+Psdi+Rad & 3,0 & $(+3,0)$ & ${ }^{*} 9$ & $(+9)$ \\
\hline Psi+Psdi+Rad+ & 0,2 & $(+0,2)$ & 1 & $(+1)$ \\
\hline Verdes & 0,3 & $(+0,3)$ & ${ }^{*} 1$ & $(+1)$ \\
\hline Psi+Psdi+Rad+ & 3,8 & $(-0,9)$ & 8 & $(-3)$ \\
\hline PRI & 2,2 & $(-0,5)$ & 3 & $(-3)$ \\
\hline PLI & 6,5 & $(-0,8)$ & 17 & $(-1)$ \\
\hline MSI & 1,5 & $(+0,4)$ & 1 & $(+1)$ \\
\hline DP & 2,0 & $(+2,0)$ & 1 & $(+1)$ \\
\hline Verdi & 0,5 & $(=)$ & 2 & $(-1)$ \\
\hline PPST & 0,4 & $(+0,2)$ & 1 & $(=)$ \\
\hline Psd'Az. & 0,1 & $(=)$ & 1 & $(=)$ \\
\hline U. Vald. & 0,4 & $(+0,4)$ & 1 & $(+1)$ \\
\hline L. Lombarda & & & & \\
\hline
\end{tabular}

* 8 escaños PSI, 1 escaño PSDI

* 1 escaño PSI

Fuente: Embajada de Italia en Madrid.

INDICE DE SIGLAS:

$\mathrm{DC}=$ Democracia Cristiana

$\mathrm{PCl}=$ Partido Comunista de Italia

PSI = Partido Socialista Italiano

PSDI= Partido Socialdemócrata Italiano

PRI = Partido Republicano Italiano

PLI= Partido Liberal Italiano

MSI = Movimiento Social Italiano
$\mathrm{RAD}=$ Radicales

$\mathrm{DP}=$ Democracia Proletaria

Psd'Az. = Partido Sardo de Acción

Ven/Pen. = Partido Popular Venetto/ Pensionistas

PPST $=$ Partido Popular Surtirolés

U. Vald. $=$ Unión Valdostana

L. Lombarda = Liga Lombarda 